Meta

Journal des tradlucteurs

Translators' Journal

\title{
An Apology for Consecutive Interpretation
}

\section{Stephen Capaldo}

Volume 25, numéro 2, juin 1980

URI : https://id.erudit.org/iderudit/002200ar

DOI : https://doi.org/10.7202/002200ar

Aller au sommaire du numéro

Éditeur(s)

Les Presses de l'Université de Montréal

ISSN

0026-0452 (imprimé)

1492-1421 (numérique)

Découvrir la revue

Citer cet article

Capaldo, S. (1980). An Apology for Consecutive Interpretation. Meta, 25(2),

244-248. https://doi.org/10.7202/002200ar d'utilisation que vous pouvez consulter en ligne.

https://apropos.erudit.org/fr/usagers/politique-dutilisation/ 


\section{An Apology for Consecutive Interpretation}

Stephen CAPAldo

Anyone who has delved into this area of applied linguistics can tell you the horror stories : interviews ruined because of a breakdown in consecutive interpretation, or simultaneous interpreters' causing scenes because of their sheer refusal to do consecutive. Well, as an individual who has been involved in interpretation now for almost five years, I would like to help balance the scales a bit by defending the teaching and practice of consecutive interpretation.

I began studying and performing this skill in 1974 and have been teaching a half-course for Anglophones in it now in Laurentian University's School of Translators and Interpreters since 1976. I feel that it is about time that something more contemporary than the admittedly excellent theoretical material of Rozan, Myers, Van Hoof and others, and more positive than the opinion of most interpreters toward consecutive, was written. The best way I personally could do this would be by analyzing my course in consecutive as it is in 1978, after already two years of evolution. I should like to discuss the course and its relation to reality in two parts :

I) the three goals of the course

II) the practical implementation of the goals

By analyzing I and II I hope to arrive at some good reasons for offering courses in consecutive interpretation.

I believe that the assumption an individual in my position must make and accept is that not all students in translation and/or interpretation schools will become consecutive interpreters. Market conditions are a problem, in addition to the fact that most interpretation is now done simultaneously. Such as assumption will perhaps, in the mind of some, divest courses in consecutive of their utilitarian value. Perhaps, but under \# 1 I hope to show that, indeed, a good course in consecutive will contain intellectual elements which are potentially applicable to any field of endeavour one may wish to enter.

I. Goals

a) To convey the problems of oral communication and public speaking.

Since a consecutive interpreter must perforce be a speaker, this is an absolutely essential part of such a course. But is it not also potentially useful for 
anyone who must deal with people orally i.e. almost every person on the face of the earth. Certainly the business world needs people who can represent companies in person and over the telephone. The academic world is always in need of people who can explain themselves clearly to their students. In short, it would be very useful to discuss such things as voice quality, voice patterns, body language, eye control, etc. What kind of a voice is pleasant to listen to and why? What kind of a speaker is pleasant to watch and relate to? Such matters are indeed extremely important to the consecutive interpreter before and during his renditions, but they are also important to anyone who is at all involved in public relations in the broad sense. People with an abrasive voice or mannerisms will have difficulty in their work, and systematic treatment of such problems within a course is one way of sensitizing the individual to possible trouble areas in this respect.

b) To convey the message of the spoken word via a note-taking system of consecutive interpretation.

This goal is obviously related in a direct way to the goal of the consecutive interpreter. When a speech is given, the interpreter must take notes on the speech and be able to reproduce the gist of it in another language up to an hour afterwards. Obviously then, the note-taking system, buoyed as it is by the interpreter's memory, is crucial to consecutive interpreter training. But once again, students will still benefit from studying a note-taking system if it teaches them to think analytically and logically. Though note-taking systems vary, there are certain basic symbols and a certain basic type of logic running throughout all of them. There are symbolic ways to reproduce statements, questions, exclamations, with the appropriate degree of emphasis on and consideration for the major and minor points of the speech. If, for example, the Prime Minister of Canada spoke on national unity in an impassioned speech, the notes might look somewhat as follows :

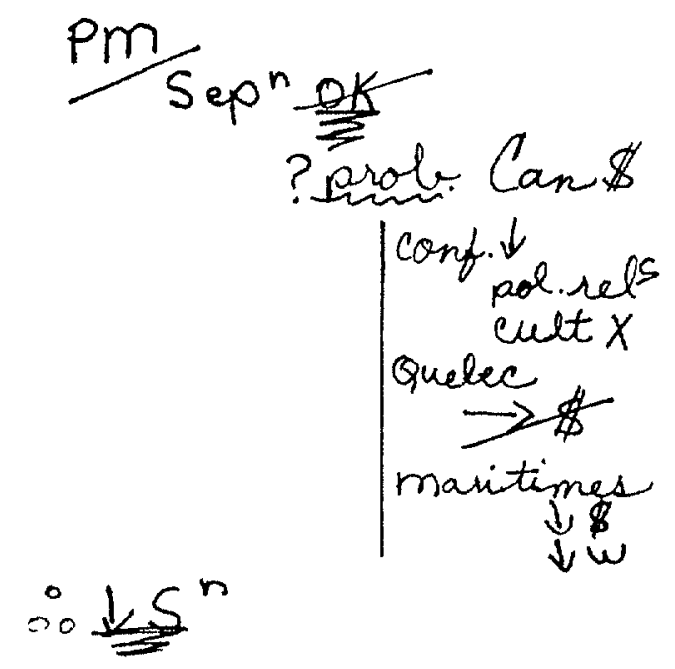


Depending on the individual interpreter's system and the amount of practice the person has had, the speech could be logically interpreted on the basis of the notes in somewhat the following way (what is in parentheses I have added for the purposes of explanation):

The Prime Minister spoke out very strongly against Quebec separatism (main point). To support his point, he noted the potential harm which would be done to the Canadian economy if Quebec were to separate. He also stated that countries would have less confidence in Canada, thus hurting political relations and cultural exchanges (brought forth as examples of "less confidence"). He then spoke about problems for Quebec as a result of separation (cf. examples, such as less incoming capital). Finally, he cited the example of the Maritimes, pointing out that their economy would be hurt and jobs would be fewer in a Confederation without Quebec. He thus concluded that separation would in no way benefit anybody.

One should note that if the interpreter is faithful and consistent, Trudeau's two main points (at the beginning and end) will be indented the least. Next in terms of indentation will be the general arguments advanced to support his initial anti-separatist premise and conclusion. Most heavily indented then would be the factual data supporting the general arguments in turn supporting the initial premise. The links between pieces of information must be clear and the passage should flow orally. Indispensable for the consecutive interpreter? Yes, but also for anyone wishing to learn to express himself thoughtfully and clearly; hence consecutive interpretation is not only a vehicle for training consecutive interpreters but also a vehicle for teaching people to think in consistent thought patterns. And of course, the real world is always in need of people who can do this.

Now I would like to discuss the means of attaining these goals and how these means may be of practical use.

\section{Practical implementation and grading}

1. 50\% on classwork (oral) - I think the reasoning here should be selfevident.

a) Student renditions of passages are obviously of great importance. Passages are read during the first part of the course in English only, after which students are expected to reproduce the main ideas based on the note-taking systems they are developing. The systems they do develop are based on initial assumptions given to the students, though the main criterion is always the comprehensibility of the notes to the interpreter. There has also been much discussion about whether to begin with unilingual renditions or work right away from one language into another. Obviously, both positions can be justified, the former by noting that it takes time to master the techniques of the note-taking system, the latter by saying that, since time is at a premium, why spend four out of twelve or thirteen weeks on a technique when there are perhaps language difficulties that should be alleviated as soon as possible. One thing is for sure: it is very difficult, if not impossible, to work on interpretation technique and basic language skills at the same time. If a teacher opts for the more technique-oriented 
approach, he must either hope that the working languages of the students are already solid or that, once the techniques are learned, the students will have outlets for improving any existing language deficiencies. If the emphasis is to be put more on interpreting with both languages immediately than on mastering technique, then it is to be hoped that technical problems can be ironed out once the languages are strong. In any event, an effective consecutive class will manage to have within it some balance between too much technique and too rapid an initiation to bilingual consecutive interpretation. And of course the advantages to studying the technique are obvious : the students learn to organize their thoughts. If they also know French and English well, they may aspire to a career in translation, interpretation, teaching, industry, journalism (cf. unilingual note-taking), government service, or any other field where being able to express oneself well in one or more languages is essential.

b) Homework assignments are collected every week and excerpts are read back in class. For the first half of the course students break up into groups of two and note-take the five major Globe and Mail editorials (Monday to Friday) appearing each week. During the second half they use their own French material and practice in groups of two, though perhaps rotating partners (rotating partners serves to force students to get along and teaches them how crucial getting along is in professional situations). It is important to give steady homework assignments and listen to the renditions of the passages, as nothing annoys students more than their mistaken belief that "if it's not graded, it's therefore worthless". This reinforces confidence in the "academic" nature of the course, though the assignments are still aimed at introducing people to a profession. The material used in both parts a) and b) is usually taken from newspapers, periodicals, or topical speeches. Material should be chosen to illustrate Rozan's seven basic principles of consecutive interpretation - the idea rather than the word, symbols, abbreviation, linkage, emphasis, verticalization and decalage and should represent a variety of speakers and speakers' styles. As much time as is practicable should be given to items intended to be heard rather than read.

c) As an obvious corollary to b), there are student demonstrations and readings counted within the classwork component of the grading scheme. This provides the variety in speaking styles and note-taking techniques necessary for the ear and eye of the consecutive interpreter, and further sensitizes people to exactly what constitutes a pleasant speaker or a pleasant person to deal with orally. Time, as ever, remains a problem here.

d) Students give their own speeches during the course. Starting in the Fall of 1978, each student will be required to give three speeches instead of just one or two: one on a general topic, one on current events, and one impromptu. This teaches the student how to deal coherently with the pressure situations which arise in any profession.

e) I have left one section in this component open for what I call "general knowledge". As we go through the course, discussions often begin on different issues of current interest and I watch very carefully to see who knows what and keeps up with what events, particularly in Canada. Admittedly, the students may 
feel that this lacks even the relative "objectivity" involved in the grading of a piece of written work, but it still represents a necessary part of the training of a consecutive interpreter or a well-educated human being.

\section{2. $25 \%$ Midterm (written)}

Consecutive interpretation of two passages, one of which is English to English, the other French to English.

This is my only compromise to the written format in the actual matter of consecutive note-taking. I do it only to appease the students, who have the idea that the grading of written work is somehow immeasurably more objective than the grading of oral work, though I personally find that a consistent teacher applies his own standards to both, the only difference being that one form of work is in writing and the other is not.

\section{3. $25 \%$ Final exam (written and theoretical)}

This is based on readings students do of certain theoretical works in the profession (Rozan, Myers, Nilski, Herbert, Van Hoof, etc.) They do a bit more writing here - in essay form - as they answer questions formulated to get them thinking about the use of the course material for interpretation and other purposes.

In part I, I have tried to give a theoretical approach to such a course and to show its appeal not just to someone who wants to do consecutive interpretation but also to anyone interested in sharpening oral communication skills. In part II, I hope to have shown how my own practical implementation of the basic premises of \# 1 does indeed provide helpful training to all comers. It is all well and good to present consecutive interpretation as the ideal in such a course, but a certain pragmatism is also necessary. Market conditions remain difficult, and student quality highly variable. We work the best way we can and try to provide a course which gives a maximum of different things to a maximum of different people. In short, while the course is obviously invaluable to a future interpreter, it is just as obvious that no university student in general will be hurt by a bit of exposure to that rare Canadian university course in which he/she will be forced to come to grips with oral communication. 